\title{
ERRATUM
}

\section{The cumulative effects of known susceptibility variants to predict primary biliary cirrhosis risk}

R Tang, H Chen, Q Miao, Z Bian, W Ma, X Feng, MF Seldin, P Invernizzi, ME Gershwin, W Liao and X Ma

Genes and Immunity (2015) 16, 238; doi:10.1038/gene.2015.2

Correction to: Genes and Immunity (2015) 16, 193-198; doi:10.1038/gene.2014.76; published online 8 January 2015.

Since the online publication of this paper, the authors have noted that the email address for the author W Liao was incorrectly listed. The correct email address is liaowi@derm.ucsf.edu.
The typesetters would like to apologise for any inconvenience caused.

This error has now been rectified, and the corrected article appears in this issue. The html and online pdf versions have also been rectified and now carry the corrected paper. 